\title{
Towards clinical definitions of lower respiratory tract infection (LRTI) for research and primary care practice in Europe: an international consensus study
}

\author{
*Giles Greene ${ }^{a}, K^{2}$ renza Hood ${ }^{b}$, Paul Littlec, Theo Verheij ${ }^{\mathrm{d}}$, Herman Goossens \\ Samuel Coenene, Christopher C Butlera
}

\footnotetext{
a Department of Primary care and Public Health, Cardiff University, Neuadd Meirionnydd Health Park, Cardiff, UK

b South East Wales Trials Unit (SEWTU), Department of Primary Care and Public Health, School of Medicine, Cardiff University, Cardiff.

'Department of Medicine, Health and Life Sciences, University of Southampton, Southamptom, UK

d Julius Center for Health, Sciences and Primary Care, University Medical Center Utrecht, The Netherlands

e Vaccine \& Infectious Disease Institute (VAXINFECTIO), University of Antwerp - Campus Drie Eiken, Antwerp, Belgium
}

\section{Received 29th November 2010; revised 18th January 2011; accepted 7th February 2011; online 20th April 2011}

\begin{abstract}
Aims: Antibiotic prescriptions for lower respiratory tract infection (LRTI) account for a large proportion of antibiotic consumption. Many of these prescriptions do not benefit patients and contribute to antibiotic resistance. Research to improve evidence-based management requires clear definitions of clinical entities. We aimed to generate definitions for common LRTIs that are applicable to clinical practice and low-intensity investigation research settings in European primary care.

Methods: Candidate definitions identified through a systematic review and a nominal group meeting were put to a Delphi panel of selected experts from Europe and the US over three rounds. The definitions achieving high consensus were then tested for face validity by an expert panel.

Results: 253 papers met our search criteria. The nominal group meeting generated highly-ranked definitions for two LRTIs. The Delphi panel considered five candidate definitions derived from the systematic review and nominal group meeting, and agreed upon definitions and open comments that the expert panel assessed for face validity.

Conclusions: We combined empirical evidence with expert opinion for the development of a set of relevant clinical and research definitions for the four most common LRTIs presenting in general practice.

(C) 2011 Primary Care Respiratory Society UK. All rights reserved.

G Greene et al. Prim Care Respir J 2011; 20(3): 299-306

http://dx.doi.org/10.4104/pcrj.2011.00034
\end{abstract}

Keywords exacerbation, asthma, COPD, diagnosis, infection, pneumonia, primary care, LRTI, bronchitis, definition, research

See linked editorial by van Weel on pg 231

The full version of this paper, with online Appendices,

is available at www.thepcrj.org

\section{Introduction}

The proportion of European patients consulting in primary care with acute cough due to lower respiratory tract infection (LRTI) who are prescribed antibiotics varies over four-fold. ${ }^{\prime}$ This variation is not associated with improved outcomes for patients. ${ }^{2}$ However, some patients may benefit from early intervention and antibiotic treatment, but feasible ways of identifying these are not well established. ${ }^{3}$ Ongoing community-based studies are needed to identify the best management for individual patients. Consequently, clear definitions are needed for including patients into such research studies in order to ensure comparability between studies and to facilitate interpretation and judgments about the applicability of findings to routine clinical care.

Some systems used for diagnostic labelling in routine

\footnotetext{
* Corresponding author: Dr Giles Greene, Department of Primary Care and Public Health, Cardiff University, Neuadd Meirionnydd Health Park, Cardiff, CF14 4YS, UK. Tel: +44 (0)2920687942 E-mail: greeneg@cardiff.ac.uk
} 
clinical care do not provide criteria for diagnostic codes - for example, the Read Code system. ${ }^{4}$ The International Classification of Primary Care (ICPC) does provide clinical criteria for some relevant diagnoses but not for all; it is not possible to identify ICDC criteria for an acute exacerbation of chronic obstructive pulmonary disease (COPD) and acute infection exacerbations of asthma, ${ }^{5}$ for example. Systems such as these are used in research based on routine data. The General Practice Morbidity Research Database relies on Read coding. Read and ICPC coding are therefore not usually applicable to definitions required for exclusion and inclusion into prospective clinical studies.

Definitions of LRTI vary, due in part to the authors' views, the audience, and the intended purpose of the definition. Definitions have been created via consensus methods for community-acquired pneumonia (CAP) and acute exacerbations of COPD (aeCOPD)., Similarly, definitions in treatment guidelines are often insufficiently specific both for clinical and research purposes. ${ }^{8}$ Many definitions do not specifically relate to primary care settings and do not cover the majority of patients with acute cough in primary care.

The aim of the present study therefore was to generate definitions for LRTI that apply to clinical presentations in European primary care for the purpose of including patients in research studies - thereby aiding judgements regarding the applicability of patients presenting routinely in the primary care setting. Due to the variation in diagnostic tools available to European general practitioners (GPs), the aim of the definitions was to categorise typical patients without the use of laboratory or imaging utilities unlikely to be universally available in primary care. We focussed on four LRTIs*

- CAP

- acute bronchitis

- aeCOPD

- acute infective exacerbations of asthma

* We undertook the process for five LRTIs initially to include a distinction between atypical and typical CAP. However, due to general agreement in the respiratory infections research community that the term atypical pneumonia has "outgrown its historical usefulness" (p14), ${ }^{9}$ the results from only the four LRTIs will be presented.

\section{Methods}

Definition development comprised three sequential processes (see Figure 1):

1. The generation of candidate definitions using a systematic review of literature and the Nominal group technique. ${ }^{10,11}$

2. A consensus process using a web-based Delphi process. ${ }^{12}$

3. A process of face validity checking by an expert panel.

\section{Generating candidate definitions}

a) Systematic review

The search strategy was devised using the Population, Intervention, Comparison and Outcome (PICO) structure, ${ }^{13}$

Figure 1. Flow diagram of the process

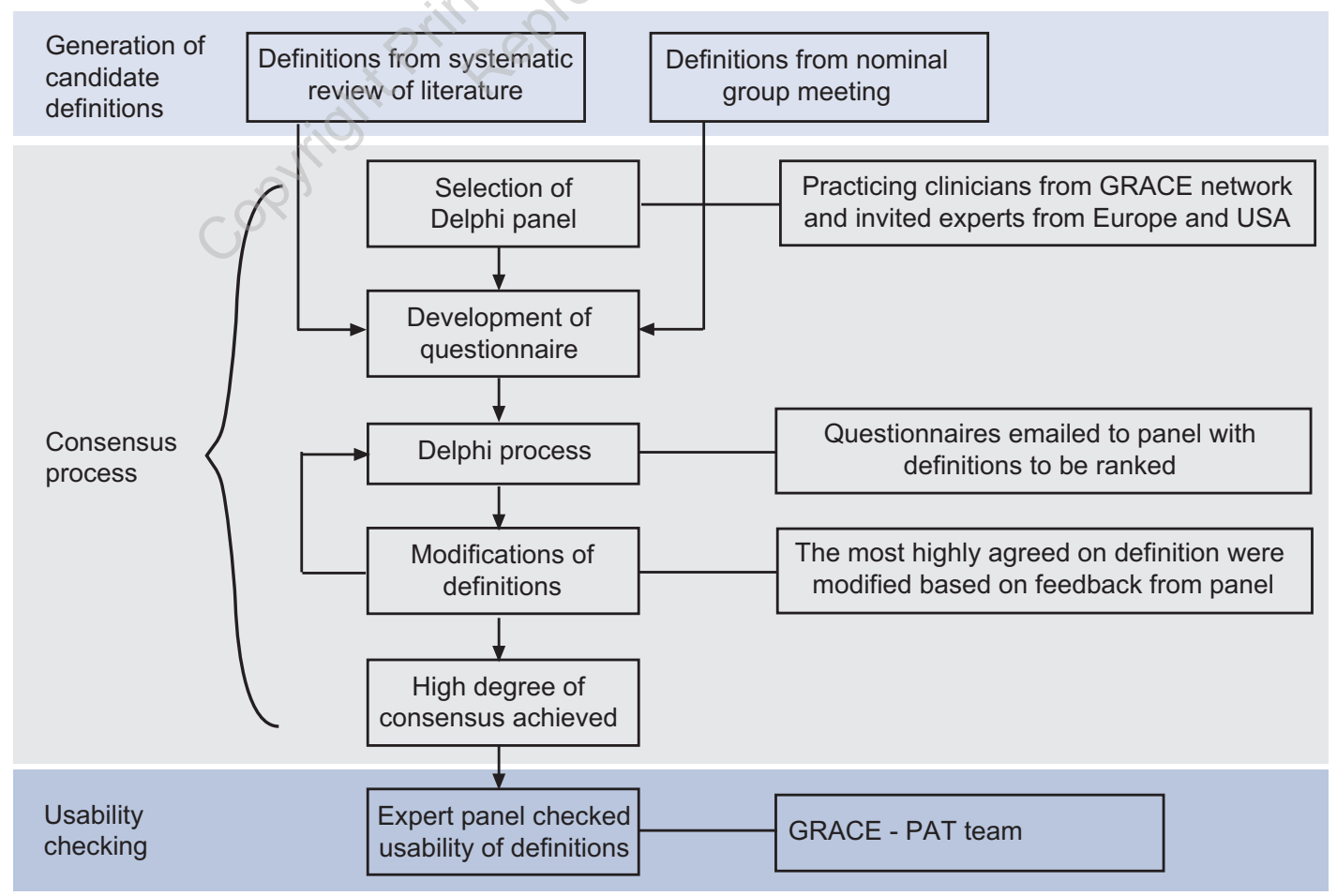




\section{Table 1. Search strategy}

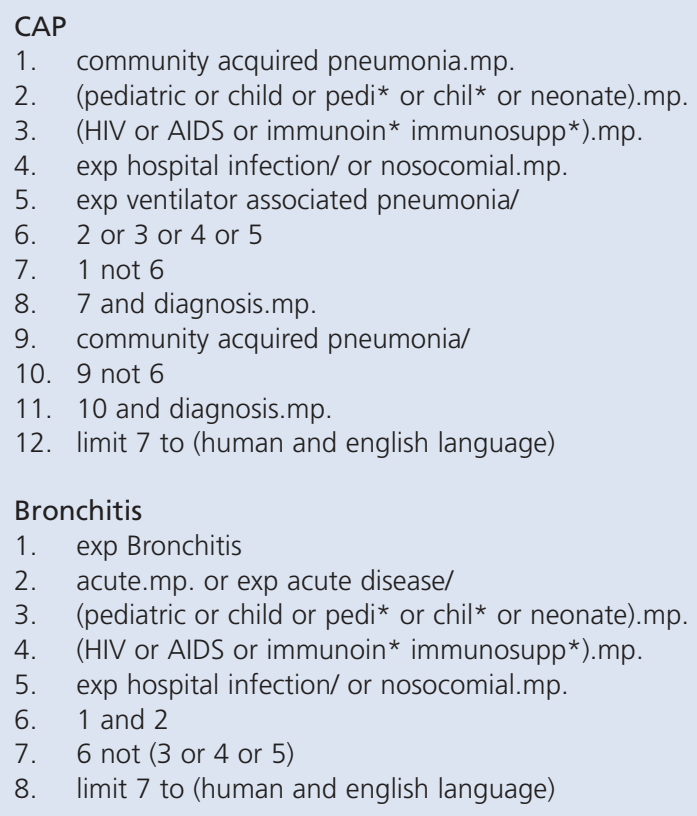

with input from both clinicians and researchers. Once an agreed strategy was devised (see Table 1) the search was run on databases with a clinical focus (Medline, EMBASE, CINAHL, AMED and British Nursing Index) from 1887-2005. The aim was to identify studies that used a clinical definition of the entity, rather than simply inclusion or exclusion criteria for patients into a trial. The search was limited to observational, non-randomised, cohort, case-control and cross-sectional study designs published in the English language. Randomised controlled trials (RCTs) were excluded as trials often require unusual assessments and special investigations to determine eligibility that are not routinely available in primary care.

\section{b) Nominal group technique}

The Nominal group technique (NGT) is a highly structured approach to a group meeting promoting the involvement of all group members. ${ }^{14,15}$ The NGT session involved 28 participants from a range of clinical and academic groups, such as general practitioners (GPs), nurses, microbiologists and epidemiological researchers in three groups. After a brief introduction, each member was required to generate items relating to four specific areas - signs and symptoms, physical findings, examinations, and special investigations - and then indicate whether it was the presence or absence of the item which was indicative of the diagnosis of a specific LRTI. This task was undertaken with no discussion. Each member contributed, in turn, one novel idea to the facilitator, who recorded it on a flip chart. After all responses had been elicited, the facilitator asked the group to clarify and/or group certain similar items to ensure accuracy. After this
aeCOPD

1. copd.mp. or exp chronic obstructive lung disease/

2. acute exacerbation.mp.

3. (pediatric or child or pedi* or chil* or neonate).mp.

4. (HIV or AIDS or immunoin* immunosupp).mp.

5. exp hospital infection/ or nosocomial.mp.

6. 3 or 4 or 5

7. 1 and 2

8. 7 not 6

9. limit 8 to (human and english language)

Infectious exacerbation of Asthma

1. exp Asthma/ or asthma.mp.

2. acute exacerbation.mp.

3. infectious exacerbation.mp.

4. (pediatric or child or pedi* or chil* or neonate).mp.

5. (HIV or AIDS or immunoin* immunosupp*).mp.

6. exp hospital infection/ or nosocomial.mp.

7. 4 or 5 or 6

8. 2 or 3

9. 1 and 8

10. 9 not 7

11. limit 10 to (human and english language)

process, group members individually assigned a rank position from first to fifth for the grouped items. The facilitator processed and collated the votes. These were then fed back to the whole group during the summing-up session.

\section{Consensus process}

The Delphi method relies on a few key principles: structuring of information flow; anonymity; and regular feedback. ${ }^{12}$ All information flows from a central facilitator enabling structured and anonymous participation. The process is carried out in rounds whereby the panel members give an opinion on a certain topic or definition, which is then retuned to the facilitator. From the literature review and NGT, five definitions for each LRTI were chosen. In order to minimise the impact of perceptions of reputable sources and maximise the focus on the definition itself, definitions were presented to the panel members without any information on their origin. We used an approach whereby each respondent put the definitions in rank order in each round and provided them with feedback on their own and group scores from the previous round in subsequent rounds. This modification from the more usual scoring of each number of items allowed the assessment of the relative weights of the different definitions and encouraged respondents to consider the group response as well as their own (see Table 2).

\section{Round 1}

Each participant was given five definitions for each LRTI and asked to rank them in order of preference. In addition, each respondent was also asked to complete a checklist of individual items ( $n=74$ generated from the literature search, plus an opportunity to 


\begin{tabular}{|c|c|c|c|}
\hline & Inputs & Outputs & Analysis \\
\hline Round 1 & $\begin{array}{l}5 \text { definitions for each LRTI identified } \\
\text { from literature NGT } \\
\text { List of clinical symptoms and signs, history, } \\
\text { physical examination results and } \\
\text { investigations for endorsement }\end{array}$ & $\begin{array}{l}\text { Rank definitions for each LRTI } \\
\text { Endorsed items }\end{array}$ & $\begin{array}{l}\text { Level of consensus on definitions } \\
\text { Agreement between individually } \\
\text { endorsed items and elements } \\
\text { of highly ranked definitions }\end{array}$ \\
\hline Round 2 & $\begin{array}{l}\text { Same } 5 \text { definitions for each LRTI as } \\
\text { Round } 1 \text { with previous ranking and group } \\
\text { ranking from Round } 1 \\
\text { Opportunity to add or remove elements } \\
\text { from top ranked definition }\end{array}$ & $\begin{array}{l}\text { Ranked definitions for each LRTI } \\
\text { Suggestions for improvement } \\
\text { for top ranked definition }\end{array}$ & $\begin{array}{l}\text { Level of consensus on definitions } \\
\text { Change scores to assess } \\
\text { level of movement of opinion }\end{array}$ \\
\hline Round 3 & $\begin{array}{l}\text { Highest ranked definitions ( } 1 \text { or } 2 \text { ) from } \\
\text { previous round with additional amended } \\
\text { definitions from commonly suggested } \\
\text { amendments }\end{array}$ & Ranked definitions for each LRTI & Level of consensus on definitions \\
\hline
\end{tabular}

contribute through a free text field) that they considered an essential part of a definition (the endorsement section).

\section{Round 2}

Each participant received the same five definitions along with their own ranking and the average rank order from the rest of the group. They were asked to re-rank the definitions. In addition, each participant was presented with a list of items, generated from the endorsement section from the previous round, and asked which, if any, should be included with the toprated definition to improve it. These were termed 'add-ons'.

\section{Round 3}

The highest ranked definition from the previous round was then modified based on the factors identified in the endorsement section and the suggested 'add-ons' from the previous two rounds. The participants were then asked to rank both the original and modified version of the highest ranked definition and second favourite definition (three in total). In addition, each participant was asked how well they felt their top-ranked definition "provided a clinical description of typical pneumonia allowing a precise description of the GRACE (Genomics to combat Resistance against Antibiotics in Community-acquired LRTI in Europe; www.grace-Irti.org) findings and a more accurate description for future primary care research." Their rating was recorded on a five-point Likert scale (1-5).

The endorsement section allowed a more in-depth exploration of the individual factors that they considered an essential part of a definition. These were later used to validate the definitions by comparing the level of coverage - i.e. the number of highly endorsed items that appear in the definition.

\section{Expert panel}

The final stage of the development process was an expert panel of the clinical leads of the GRACE Patient Platform (GRACE-PAT). The purpose of this meeting was to consider the results of the Delphi exercise and to consider any further modifications to definitions that might increase their accuracy and appropriateness to their intended use. This was a smaller and more focused consensus process. The meeting focused on the readability of each definition and addressing specific comments made by the Delphi panel.

\section{Subjects}

Panel members were selected because of their research record or clinical interest in the field of respiratory infections in primary care. In addition, we aimed to include experts from a range of contrasting countries. The GRACE Network of Excellence was utilised with invitations sent to all National Network Coordinators (NNCs) and clinical workpackage leaders. ${ }^{1}$ Additional experts were invited from Europe and the USA including members of CHAMP (Changing behaviour of Health care professionals And the general public towards a More Prudent use of anti-microbial agents) and GRIN (General practice Respiratory Infections Network). Twenty-seven experts were asked to participate, with 18 agreeing to engage actively in the process.

\section{Analysis: measuring consensus}

The summed score and the number of first place ranks were used to indicate consensus. These were chosen as preferable to the median and IQR of ranking used in many Delphi studies due to the limited number of options in the task $(n=5)$. The number of first place ranks was used as the predominant measure of consensus due to the discrete nature of the task. The level of consensus was pre-set at $70 \%$ absolute agreement, whereby consensus was achieved if one definition was ranked in first place by 12 or more of the panel by the end of the process. Comparisons were made between the median ranking position and inter-quartile range (IQR), and the summed score and to measure agreement. The change in total score from Round 1 to Round 2 was also noted to assess the degree at which agreement converged. A minus change score denoted an increase in agreement demonstrating more higher ranking positions. The expert panel considered the final definitions as a whole to make final clarification and wordings amendments. 


Table 3. Scoring and derived definitions from NGT*
\begin{tabular}{lll} 
LRTI & Top individual items (score) & Definition \\
\hline CAP & 1. Focal chest signs and symptoms (23) & $\begin{array}{l}\text { Rapid onset with focal chest signs and symptoms (any abnormal findings on } \\
\text { auscultation, dyspnoea and observable breathing difficulties) and an acute } \\
\text { cough, which may or may not be productive in a generally unwell patient } \\
\text { 2. Cough +/- sputum (14) }\end{array}$ \\
& $\begin{array}{ll}\text { 3. Exceptional unwellness (13) } \\
\text { 4. Without runny nose (11) }\end{array}$ & $\begin{array}{l}\text { Requires the presence of both a cough with an acute onset (around 2-3 days) } \\
\text { and abnormal breathing sounds on expiration but only when both asthma } \\
\text { 5. Without Sore throat (11) }\end{array}$ \\
\hline Acute Bronchitis COPD have been ruled out \\
& $\begin{array}{l}\text { 1. Cough (34) } \\
\text { 2. Acute onset (27) }\end{array}$ & \\
& 3. Presence of Expiratory sounds (16) & \\
4. Lack of generalised crackles (14) & \\
\hline
\end{tabular}

*Each participant ranked his or her top five items. Their five votes are valued from ' 1 ' to ' 5 ' points, with higher scores indicating the greatest value for them.

\section{Results}

\section{Generating candidate definitions}

\section{a) Systematic review}

The search of five databases identified 1476 articles for consideration, of which over half were excluded at the abstract stage $(n=936)$. The main reason for exclusion was that the paper related to the microbiology of pathogens. The remaining 537 full paper articles were reviewed; a further 239 were excluded for not containing a a suitable definition, with 45 articles that could not be retrieved. Full papers could not be retrieved because either the reference related to an abstract only, or the article was published in journals that were not accessible through the British library (e.g. a small local medical journal), or the paper was very old $A$ total of 253 papers with usable definitions was generated. The selected candidate definitions $(n=18)$ were selected as appearing in the most cited (citation index based on ISI Web of Knowledge) articles. A full list of included studies is shown in Appendix, available online at www.thepcrj.org.

\section{b) Nominal group technique}

As relatively small numbers participated in the NGT, only two of the four definitions were considered; acute bronchitis and CAP. For both definitions the highest ranked item was considered a defining symptom and placed first in the definition (see table 3 for included definition components). For acute bronchitis and CAP, the top five items were used. Full definitions are presented in Appendix 2 (available online at www.thepcrj.org).

\section{Consensus process}

Of the 27 experts invited, 18 agreed to be actively engaged in the process. The results of the Delphi rounds and suggested addons for each definition are detailed in Appendix 3 (available online at www.thepcrj.org)

a) Community acquired pneumonia (CAP)

Definition 4 (original)

An acute chest infection, accompanied by a cough, fever and increased respiratory rate, and the presence of an acute infiltrate on a chest radiograph, or auscultatory findings consistent with pneumonia (such as altered breath sounds and/or localised rales), in a patient not hospitalised or residing in a long-term-care facility for 14 days before onset of symptoms.

\section{Definition 4 (modified)}

The onset is rapid with focal chest signs and symptoms (any abnormal findings on auscultation, dyspnoea and observable breathing difficulties) and an acute productive or nonproductive cough, in a feverish, generally unwell patient with no signs of cold e.g. runny nose and sore throat.

\section{Result}

The original definition 4 achieved the highest agreement, the lowest median and total score in Round 3.

b) Acute bronchitis

\section{Definition 1 (original)}

The acute or subacute onset of productive cough in a patient with no history of chronic pulmonary disease and without evidence of pneumonia or sinusitis.

\section{Definition 1 (modified)}

The acute onset of a cough, with or without sputum, in a patient with no history of chronic pulmonary disease and without evidence of community-acquired pneumonia.

Result

The modified definition achieved the highest level of agreement.

c) Acute exacerbation of COPD (aeCOPD) Definition 1 (original)

A sustained worsening of the patient's condition, from the stable state and beyond normal day-to-day variations, that is acute in onset and necessitates a change in medication in a patient with underlying COPD.

\section{Definition 1 (modified)}

A sustained worsening of the patient's condition, from the stable state and beyond normal day-to-day variations, that is acute in onset and necessitates a change in medication in a 
patient with underlying COPD. Clinical symptoms include cough, and dyspnoea.

\section{Definition 2 (second favourite)}

A combination of, or all three of; worsening of dyspnoea, increase in sputum purulence and increase in sputum volume, as well as one of the following clinical criteria: an upper respiratory tract infection in the past 5 days; fever without another apparent cause; increased wheezing; increased cough; or increase in respiratory rate or heart rate by $20 \%$ above baseline.

\section{Result}

Both the modified and the 2nd favourite definitions were passed on to the expert panel stage.

d) Acute infectious exacerbation of asthma

\section{Definition 5 (original)}

Increase in asthma symptoms and a productive cough (an increase and/or change in colour (e.g. green or yellow) of sputum).

\section{Definition 5 (modified)}

The acute onset of an increase in asthma symptoms (e.g. dyspnoea, wheeze) and a productive cough (an increase and/or change in colour (e.g. green or yellow) of sputum).

\section{Result}

The modified statement achieved the greatest level of consensus.

\section{Expert panel}

The expert panel met after the third round of the Delphi exercise and were provided with the consensus definitions and open comments from individuals as to the 'usability' of the emerging definitions.

The final expert panel discussed the inclusion of $\mathrm{x}$-ray findings in the definition of CAP, given that this investigation is not always easily or routinely available to GPs in all countries. However, since it is available in some countries and given that the use of radiographic evidence is prevalent in the literature, it was decided to include it. It was also decided to stress the clinical components of the definition by stating them first and therefore ending up with a definition that could be used without x-ray results in contexts where this is not easily available. A minor wording change was made to clarify that both rales and breath sounds should be expressly described as localised for the purposes of this definition.

The ranking of acute bronchitis in the third round was not decisive, with the number of first rank votes evenly distributed. The decision was taken to examine the influence of the modification to the very highly ranked definition from Round 2 . The main difference between the original and the modified definitions were the description of sputum (a productive cough versus a cough with signs of sputum production). In order to resolve this difference the panel felt the phrase 'with evidence of

\section{Table 4. Final definitions chosen by the Delphi and those modified by by Expert panel}

\begin{tabular}{|c|c|c|}
\hline & Consensus derived definitions & Expert panel modified definitions \\
\hline $\begin{array}{l}\text { Community acquired } \\
\text { Pneumonia }\end{array}$ & $\begin{array}{l}\text { An acute infection of the pulmonary parenchyma that } \\
\text { is associated with at least some symptoms of acute } \\
\text { infection, accompanied by the presence of an acute } \\
\text { infiltrate on a chest radiograph or auscultatory } \\
\text { findings consistent with pneumonia (such as altered } \\
\text { breath sounds and/or localised rales), in a patient not } \\
\text { hospitalised or residing in a long-term-care facility for } \\
14 \text { days before onset of symptoms. }{ }^{16}\end{array}$ & $\begin{array}{l}\text { An acute infection of the pulmonary parenchyma that } \\
\text { is associated with at least some symptoms of acute } \\
\text { infection, accompanied by auscultatory findings } \\
\text { consistent with pneumonia (such as localised breath } \\
\text { sounds and localised rales) and/or the presence of an } \\
\text { acute infiltrate on chest radiograph, in a patient not } \\
\text { hospitalised or residing in a long-term care facility for } \\
14 \text { days before onset of symptoms. }\end{array}$ \\
\hline Acute Bronchitis & $\begin{array}{l}\text { The acute or subacute onset of productive cough in a } \\
\text { patient with no history of chronic pulmonary disease } \\
\text { and without evidence if pneumonia or sinusitis. }{ }^{17}\end{array}$ & $\begin{array}{l}\text { The acute or subacute onset of cough accompanied } \\
\text { with evidence of sputum production in a patient with } \\
\text { no history of chronic pulmonary disease and no } \\
\text { evidence of pneumonia or sinusitis. }\end{array}$ \\
\hline AeCOPD & $\begin{array}{l}\text { A combination of, or all three of; worsening of } \\
\text { dyspnoea, increase in sputum purulence and increase } \\
\text { in sputum volume, as well as one of the following } \\
\text { clinical criteria: an upper respiratory tract infection in } \\
\text { the past } 5 \text { days; fever without another apparent } \\
\text { cause; increased wheezing; increased cough; or } \\
\text { increase in respiratory rate or heart rate by } 20 \% \\
\text { above baseline. }{ }^{18}\end{array}$ & \\
\hline $\begin{array}{l}\text { Acute infectious } \\
\text { exacerbation of asthma }\end{array}$ & $\begin{array}{l}\text { Increase in asthma symptoms and a productive cough } \\
\text { (an increase and/or change in colour (e.g. green or } \\
\text { yellow) of sputum). }{ }^{19}\end{array}$ & $\begin{array}{l}\text { The acute onset of an increase in asthma symptom } \\
\text { (e.g. dyspnoea, wheeze), a productive cough (an } \\
\text { increase and/or change in colour (e.g. green or } \\
\text { yellow) of sputum) and/or other symptoms suggestive } \\
\text { of infection. }\end{array}$ \\
\hline
\end{tabular}


sputum production' would cover both aspects equally.

A few members from the Delphi panel had asked whether the definition for aeCOPD should include the term "in the absence of pneumonia". The GRACE-PAT team agreed that the definition created by the Delphi process was a tacit description of 'uncomplicated' aeCOPD and therefore that naturally excluded pneumonia. It was therefore agreed that the definition generated by the Delphi process was sufficient and did not require editing.

Participants commented that some cases of acute infectious exacerbation of asthma are not associated with a productive cough. This may relate to the age or 'vitality' of the patient. Therefore, the selected definition was modified to clarify the need for evidence of an inflammatory response, usually an increase or developing of mucus production, to an infection. It was stated that the signs of infection are various, so to efficiently incorporate all factors it was decided that the term 'other symptoms suggestive of infection' should be included.

\section{Discussion}

This study produced consensus definitions of four LRTIs for use in primary care and primary care research across Europe. The use of multiple consecutive methods to develop definitions has been able to provide a product that is more robust than could have been achieved by each method individually. Due to the subjective nature of the consensus process it was useful to have a consecutive process to validate the results of the previous stage. The definitions provided by this study are not meant to be authoritative but a place to start the debate of clinical descriptions - relevant to primary care-based research and clinical practice - of the major LRTIs that present in GPs' consulting rooms across Europe. They are meant to be particularly useful for research settings where intensive laboratory and radiological investigations are not feasible.

\section{Developing candidate definitions}

We took two approaches to identifying candidate definitions; one relied on a review of definitions taken from previously published studies and therefore tapped into established approaches. However, this may have been too research-focussed to provide clinically relevant definitions and therefore the nominal group technique was used to provide a more 'bottom up' approach for a candidate definition. The final definitions tended to relate more to those from the literature than those that emerged from the nominal groups. The systematic review was limited mainly by the inclusion of articles published only in the English language, a constraint imposed by time and resources. Given these time and resource limitations, we focused our main effort on the consensus strategies.

\section{Developing consensus}

The Delphi process was a systematic method for choosing the best definition arising from the review and NGT. The Delphi process was able to reach a high level of consensus over three rounds and the feedback from the Delphi panel has been extremely favourable. The task was completed with very few errors and the panel reported little or no confusion with the instructions for the task or the task itself.

A number of factors aided in the completion of the task and the quality of the definitions produced. The panel members were experts in respiratory infection as well as research-supportive practising clinicians, which added to the range of perspectives. ${ }^{20}$ There was a $100 \%$ participation rate for all three Delphi rounds for those who agreed to take part. In addition, panel members often gave detailed comments from round to round. The Delphi process was able to elicit high levels of agreement from experts from across Europe and the USA. This level of expert involvement has not been achieved in this area before, where consensus is usually drawn from experts within a country (to produce national guidelines) or via a face to face/conference structure. The use of a Delphi approach could be considered preferable to consensus by meetings as it avoids unbalanced influence from dominant members of a panel.

Our definitions of CAP differ from the ICPC-2: Code (R 81) for pneumonia in that there is only one criterion for the ICPC diagnosis, namely evidence of consolidation. Our definition emphasises symptoms and examination findings and/or the presence of consolidation. We also provide relevant contextual criteria to define the community-acquired aspect (see Table 4).

The ICD criteria for acute bronchitis (ICPC-2: Code R78) is "cough and fever with scattered or generalised abnormal chest signs". Our definition includes the acute or subacute onset with "sputum production in patients with no history of COPD and no evidence of pneumonia or sinusitis".

The ICPC-2 criteria for COPD includes only "objective evidence of airway obstruction, not/partially relieved by bronchodilators." Our definition for aeCOPD requires "a combination, or all three of worsening or increase in respiratory rate or heart rate by $20 \%$ above baseline."

The ICPC-2 criterion for asthma is "recurrent episodes of reversible acute bronchial obstruction with wheeze/dry cough; or a diagnostic test meeting currently accepted criteria for asthma." Our definition for acute infectious exacerbation focuses on acute onset of increase in asthma symptoms, productive cough and/ or change in sputum colour and/or other symptoms suggestive of infection.

The definitions we developed are therefore more specific for research rather than being useful for general administrative purposes, while at the same time maintaining relevance to everyday clinical practice through not being over-reliant on investigations. As the focus of our main study was on acute cough, we developed definitions for acute exacerbations of COPD and acute infectious exacerbations of asthma which we were not able to find in the ICPC-2. 


\section{Acknowledgements}

Thanks to all panel members and NGT members.

\section{Conflicts of interest}

There are no competing interests for any of the authors.

\section{Contributorship}

GG carried out the review of literature, the Delphi study and the first draft. CB and $\mathrm{KH}$ were involved heavily in the design, analysis and reporting of all aspects of the study. $\mathrm{KH}$ and GG undertook the NGT. All others were involved in the conception of the study and have made contributions to the analysis and preparation of the manuscript.

\section{Funding}

This study is part of the GRACE study funded by the 6th Framework Programme of the European Commission under the reference LSHM-CT-2005-518226. The South East Wales Trials Unit is funded by the National Institute for Social Care and Health Research.

\section{References}

1. Butler CC, Hood K, Verheij $\mathrm{T}$, et al. Variation in antibiotic prescribing and its impact on recovery in patients with acute cough in primary care: prospective study in 13 countries. BMJ 2009;338:b2242. http://dx.doi.org/ 10.1136/bmj.b2242

2. Butler CC, Hood K, Kelly MJ, et al. Treatment of acute cough/lower respiratory tract infection by antibiotic class and associated outcomes: a 13 European country observational study in primary care. Antimicrob Chemother 2010; 65(11):2472-8. http://dx.doi.org/10.1093/jac/dkq336

3. Stanton N, Francis NA, Butler CC. Reducing uncertainty in managing respiratory tract infections in primary care. Br J Gen Pract 2010;60:466-75.

4. Bentley T, Price C, Brown P. "Structural and lexical features of successive versions of the Read Codes". The Proceedings of the 1996 Annual Conference of The Primary Health Care Specialist Group of the British Computer Society. (13th-15th September 1996)

5. Marc Verbeke, M, Schrans, D, Deroose, S, J Maeseneer. The International Classification of Primary Care (ICPC-2): an essential tool in the EPR of the GP. Stud Health Technol Inform 2006;124:809-14.

6. Macfarlane J, Lewis SA, Macfarlane R, Holmes W. Contemporary use of antibiotics in 1089 adults presenting with acute lower respiratory tract illness in general practice in the U.K.: implications for developing management guidelines. Resp Med 1997;91:427-34. http://dx.doi.org/10.1016/S09546111(97)90258-4
7. BTS guidelines for the management of chronic obstructive pulmonary disease. The COPD Guidelines Group of the Standards of Care Committee of the BTS. Thorax 1997;52 Suppl 5:S1-28.

8. Wood J, Butler C, Hood K, et al. Antibiotic prescribing for adults with acute cough/LRTI: congruence with guidelines. Eur Respir J erj01458-2010; published ahead of print 2011, http://dx.doi.org/10.1183/09031936.00145810

9. Guidelines for the management of community-acquired pneumonia in adults: update 2009. British Thoracic Society Community acquired Pneumonia in Adults Guideline Group. Thorax 2009;64:Suppl: III

10. Delbecq AL, Van de Ven AH. A group process model for problem identification and program planning. Journal of Applied Behavioral Science 1971;7:466-92. http://dx.doi.org/10.1177/002188637100700404

11. Jones J, Hunter D. Consensus methods for medical and health services research. BMJ 1995;311:376-80.

12. Dalkey N, Helmer O. An experimental application of the Delphi method to the use of experts. Management science 1963;9:458-67. http://dx.doi.org/ 10.1287/mnsc.9.3.458

13. Armstrong EC. The well-built clinical question: the key to finding the best evidence efficiently. Wisconsin Med J 1999;48:350-5.

14. Delbecq AL, Van de Ven $A H$, Gustafson $D H$. Group techniques for program planning: A guide to nominal group and Delphi processes. Green Briar Press, Middleton, Wl; 1975.

15. Van de Ven $A H$, Delbecq $A L$. The nominal group as a research instrument for exploratory health studies. Am J Public Health 1972;62:337-42. http://dx.doi.org/10.2105/AJPH.62.3.337

16. Bartlett JG, Dowell SF, Mandell LA, File Jr TM, Musher DM, Fine MJ: Practice guidelines for the management of community acquired pneumonia in adults. Clinical infectious diseases 2000;31:347-82. http://dx.doi.org/10.1086/313954

17. Gonzales R, Sande M. What will it take to stop physicians from prescribing antibiotics in acute bronchitis? Lancet 1995;345:665-6. http://dx.doi.org/10.1016/S0140-6736(95)90861-7

18. McCrory DC, Brown C, Gelfand SE, Bach PB. Management of acute exacerbations of COPD. Chest 2001;119:1190. http://dx.doi.org/10.1378/ chest.119.4.1190

19. Crockett A. Asthma: your questions answered. Elsevier Health Sciences; 2003.

20. Pill J. The Delphi method: substance, context, a critique and an annotated bibliography. Socio-Economic Planning Science 1971;5:57-71. http://dx.doi.org/10.1016/0038-0121(71)90041-3 
Appendix 1: List of papers from which definitions for the Delphi process were taken.

\section{CAP}

Arnold, F. W., Ramirez, J. A., McDonald, L. C., \& Xia, E. L., Hospitalization for community-acquired pneumonia: the pneumonia severity index vs clinical judgment. Chest 124(1); 2003, 121-124.

Bartlett, J. G., Dowell, S. F., Mandell, L. A., File Jr, T. M., Musher, D. M., \& Fine, M. J., Practice guidelines for the management of community-acquired pneumonia in adults. Infectious Diseases Society of America.[see comment]. Clinical Infectious Diseases; 31(2); 2000, 347-382.

Lieberman, D., \& Lieberman, D., Community-acquired pneumonia in the elderly: a practical guide to treatment. Drugs \& Aging; 17(2); 2000, 93-105.

Metlay, J. P., Kapoor, W. N., \& Fine, M. J., Does this patient have community-acquired pneumonia? Diagnosing pneumonia by history and physical examination. JAMA; 278(17); 1997, 1440-1445.

\section{Acute Bronchitis}

Bent, S., Saint, S., Vittinghoff, E., \& Grady, D., Antibiotics in acute bronchitis: a meta-analysis. American Journal of Medicine 107(1):62-7, 1999 Jul.

Macfarlane, J., Holmes, W., Gard, P., Thornhill, D., Macfarlane, R., \& Hubbard, R., Reducing antibiotic use for acute bronchitis in primary care: blinded, randomised controlled trial of patient information leaflet.[see comment]. BMJ 324(7329):91-4, 2002 Jan 12.

Matsuyama, W., Hashiguchi, T., Matsumuro, K., Iwami, F., Hirotsu, Y., Kawabata, M., et al., Increased serum level of vascular endothelial growth factor in pulmonary tuberculosis. American Journal of Respiratory \& Critical Care Medicine; 162(3); 2000, 1120.

Oeffinger, K. C., Snell, L. M., Foster, B. M., Panico, K. G., \& Archer, R. K., Treatment of acute bronchitis in adults. A national survey of family physicians.[see comment]. Journal of Family Practice; 46(6); 1998, 469-675.

\section{aeCOPD}

Almagro, P., Calbo, E., Ochoa de Echaguen, A., Barreiro, B., Quintana, S., Heredia, J. L., et al., Mortality after hospitalization for COPD. Chest; 121(5); 2002, 1441-1448.

Collet, J. P., Shapiro, S., Ernst, P., Renzi, P., Ducruet, T., Robinson, A., et al., Effects of an immunostimulating agent on acute exacerbations and hospitalizations in patients with chronic obstructive pulmonary disease. American Journal of Respiratory Critical Care Medicine; 156(6); 1997, 1719-1724.

Kessler, R., Faller, M., Fourgaut, G., Mennecier, B., \& Weitzenblum, E., Predictive factors of hospitalization for acute exacerbation in a series of 64 patients with chronic obstructive pulmonary disease. American Journal of Respiratory \& Critical Care Medicine; 159(1); 1999, 158-164.

McCrory, D. C., Brown, C., Gelfand, S. E., \& Bach, P. B., Management of acute exacerbations of COPD: a summary and appraisal of published evidence.[comment]. Chest; 119(4); 2001, 1190-1209.

Soto, F. J., \& Varkey, B., Evidence-based approach to acute exacerbations of COPD. Current Opinion in Pulmonary Medicine; 9(2); 2003, 117-124.

\section{Acute infection exacerbation of asthma}

Busse, W. W., \& Lemasnske Jr, R. F. (2004). Management of asthma exacerbations. Thorax, 59(7), 545-546.

Crockett, A. (2003) Asthma: Your questions answered. Churchill Livingstone; 1 edition

Johnston, S. L., Blasi, F., Black, P. N., Martin, R. J., Farrell, D. J., Nieman, R. B., et al., The effect of telithromycin in acute exacerbations of asthma.[see comment]. New England Journal of Medicine; 354(15); 2005, 1589-1600.

Martin, J. G., Siddiqui, S., \& Hassan, M., Immune responses to viral infections: Relevance for asthma. Paediatric Respiratory Reviews

7(Suppl 1); 2005, S125-S127

Wark, P. A., Johnston, S. L., Moric, I., Simpson, J. L., Hensley, M. J., \& Gibson, P. G., Neutrophil degranulation and cell lysis is associated with clinical severity in virus-induced asthma. European Respiratory Journal; 19(1); 2002, 68-75. 
G Greene et al.

Appendix 2: Definitions from Nominal group meeting.

\section{CAP}

The onset of typical pneumonia is rapid with focal chest signs and symptoms (any abnormal findings on auscultation, dyspnea and observable breathing difficulties) and an acute cough, which may or may not be productive in a generally unwell patient with no signs of cold e.g. runny nose and sore throat.

\section{Acute Bronchitis}

Requires the presence of both a cough with an acute onset (around 2-3 days) and abnormal breathing sounds on expiration but only when both asthma and COPD have been ruled out. 
Towards clinical definitions of LRTI

Appendix 3: Delphi results from all three rounds.

CAP

Ranking section ( 1 is the highest value)

Round 1

Round 2

\begin{tabular}{|c|c|c|c|c|c|c|c|c|}
\hline & & Round 1 & & & Round 2 & & & \\
\hline Definition & Coverage (\%) & Median (IQR) & Total score & $\begin{array}{l}\text { 1st place } \\
\text { votes }\end{array}$ & Median (IQR) & Total score & $\begin{array}{l}\text { 1st place } \\
\text { votes }\end{array}$ & $\begin{array}{l}\text { Change } \\
\text { score }\end{array}$ \\
\hline 1 & 57 & $4(3-4)$ & 64 & 2 & $4.5(4-5)$ & 79 & 0 & -15 \\
\hline 2 & 55 & $3(2-5)$ & 58 & 4 & $4(4-5)$ & 74 & 1 & -16 \\
\hline 3 & 51 & $3(2-4)$ & 51 & 4 & $3(2.25-3)$ & 49 & 0 & +2 \\
\hline 4 & 62 & $2(1-4)$ & 48 & 6 & $1(1-1)$ & 22 & 16 & +26 \\
\hline $5^{*}$ & 76 & $2(2-5)$ & 49 & 2 & $2(2-3)$ & 46 & 1 & +3 \\
\hline
\end{tabular}

\begin{tabular}{|lc|}
\hline Suggested 'add-ons' & \\
\hline Cough & 12 \\
\hline Fever & 8 \\
\hline Acute onset & 5 \\
\hline Increased Respiratory rate & 6 \\
\hline Increased temperature & 4 \\
\hline Increased pulse rate & 3 \\
\hline Crackles on auscultation & 4 \\
\hline Chest x-ray & 2 \\
\hline Rapid rate of deterioration & 2 \\
\hline
\end{tabular}

\begin{tabular}{|lll|}
\hline Round 3 & \\
\hline & Median (IQR) & Total score \\
\hline Original & $1(1.00-2.00)$ & 24 \\
\hline Modified & $2(1.00-2.00)$ & 27 \\
\hline Rating & $4(4.00-4.00)$ & \\
\hline & & \\
\hline
\end{tabular}


G Greene et al.

\section{Appendix 3: Delphi results from all three rounds continued.}

\section{Acute Bronchitis Round 1}

\section{Ranking section (1 is the highest value)}

Round 1

Round 2

\begin{tabular}{|c|c|c|c|c|c|c|c|c|}
\hline & & Round 1 & & & Round 2 & & & \\
\hline Definition & Coverage (\%) & Median (IQR) & Total score & $\begin{array}{l}\text { 1st place } \\
\text { votes }\end{array}$ & Median (IQR) & Total score & $\begin{array}{l}\text { 1st place } \\
\text { votes }\end{array}$ & $\begin{array}{l}\text { Change } \\
\text { score }\end{array}$ \\
\hline 1 & 75 & $2(1-2)$ & 34 & 5 & $1(1-1)$ & 25 & 13 & -9 \\
\hline 2 & 52.9 & $2(1-4)$ & 47 & 5 & $2(1.25-2)$ & 32 & 5 & -15 \\
\hline 3 & 36.4 & $4(3-4)$ & 61 & 4 & $4(3-4.75)$ & 71 & 0 & +10 \\
\hline 4 & 57.4 & $3.5(2-5)$ & 58 & 2 & $3(3-4)$ & 62 & 0 & +4 \\
\hline $5^{*}$ & 71.7 & $3.5(3-5)$ & 70 & 2 & $5(4-5)$ & 80 & 0 & +10 \\
\hline
\end{tabular}

\begin{tabular}{|ll|}
\hline Suggested 'add-ons' & \\
\hline Cough & 1 \\
\hline Absence of COPD & 2 \\
\hline Acute onset & 3 \\
\hline Rhonchi on auscultation & 2 \\
\hline ESR & 0 \\
\hline
\end{tabular}

\begin{tabular}{|lll|}
\hline \multicolumn{1}{|l|}{ Round 3 } & \\
\hline & Median (IQR) & Total score \\
\hline Original & $2(1.00-2.00)$ & 35 \\
\hline Modified & $2(1.00-3.00)$ & 30 \\
\hline 2nd favourite & $3(1.00-3.00)$ & 37 \\
\hline Rating & $4(3.50-4.00)$ & \\
\hline & & \\
\hline
\end{tabular}


Towards clinical definitions of LRTI

\section{Appendix 3: Delphi results from all three rounds continued.}

\section{aeCOPD Round 1}

\section{Ranking section ( 1 is the highest value)}

Round 1

Round 2

\begin{tabular}{|lllllllll|}
\hline Refinition & Coverage (\%) & Median (IQR) & Total score & $\begin{array}{l}\text { 1st place } \\
\text { votes }\end{array}$ & Median (IQR) & $\begin{array}{c}\text { Total score } \\
\begin{array}{l}\text { 1st place } \\
\text { votes }\end{array}\end{array}$ & $\begin{array}{c}\text { Change } \\
\text { score }\end{array}$ \\
\hline 1 & 47 & $2(1-3)$ & 38 & 5 & $1(1-2)$ & 28 & 11 & -10 \\
\hline 2 & 61.3 & $2(1-3)$ & 47 & 5 & $2(2-2)$ & 37 & 4 & -10 \\
\hline 3 & 70.6 & $2.5(2-3)$ & 45 & 4 & $3(2-3)$ & 47 & 3 & +2 \\
\hline 4 & 52.9 & $4.5(4-5)$ & 72 & 2 & $5(5-5)$ & 88 & +16 \\
\hline 5 & 35.3 & $4(4-4)$ & 68 & 2 & $4(4-4)$ & 70 & 0 & +2 \\
\hline
\end{tabular}

\begin{tabular}{|ll|}
\hline Suggested 'add-ons' & \\
\hline Cough & 6 \\
\hline Dyspnoea & 7 \\
\hline Shortness of breath & 5 \\
\hline Increased Respiratory rate & 2 \\
\hline Wheeze & 2 \\
\hline Chest x-ray & 2 \\
\hline
\end{tabular}

\begin{tabular}{|lll|}
\hline Round 3 & \\
\hline & Median (IQR) & Total score \\
\hline Original & $2(2.00-3.00)$ & 40 \\
\hline Modified & $2(1.00-2.00)$ & 31 \\
\hline 2nd favourite & $1(1.00-3.00)$ & 31 \\
\hline Rating & $4(4.00-4.00)$ & \\
\hline & & \\
\hline
\end{tabular}


G Greene et al.

\section{Appendix 3: Delphi results from all three rounds continued.}

\section{Acute infectious exacerbation of asthma Round 1}

\section{Ranking section (1 is the highest value)}

Round 1

Round 2

\begin{tabular}{|c|c|c|c|c|c|c|c|c|}
\hline & & Round 1 & & & Round 2 & & & \\
\hline Definition & Coverage $(\%)$ & Median (IQR) & Total score & $\begin{array}{l}\text { 1st place } \\
\text { votes }\end{array}$ & Median (IQR) & Total score & $\begin{array}{l}\text { 1st place } \\
\text { votes }\end{array}$ & $\begin{array}{l}\text { Change } \\
\text { score }\end{array}$ \\
\hline 1 & 60.8 & $4(2-4)$ & 64 & 0 & $5(5-5)$ & 86 & 0 & +22 \\
\hline 2 & 61.2 & $3(3-5)$ & 64 & 0 & $3(2-4)$ & 52 & 2 & -12 \\
\hline 3 & 54.9 & $3(2-4)$ & 56 & 3 & $4(3-4)$ & 64 & 1 & +8 \\
\hline 4 & 37 & $2(2-4)$ & 48 & 3 & $2(1-2)$ & 33 & 6 & -15 \\
\hline 5 & 33.3 & $1(1-3)$ & 38 & 12 & $1.5(1-2.75)$ & 35 & 9 & -3 \\
\hline
\end{tabular}

\begin{tabular}{|ll|}
\hline Suggested 'add-ons' & \\
\hline Dyspnoea & 4 \\
\hline Increased Respiratory rate & 1 \\
\hline Acute onset & 7 \\
\hline Wheeze & 3 \\
\hline PCR & 1 \\
\hline
\end{tabular}

\begin{tabular}{|lll|}
\hline Round $\mathbf{3}$ & \\
\hline & Median (IQR) & Total score \\
\hline Original & $2(2.00-3.00)$ & 39 \\
\hline Modified & $1(1.00-2.00)$ & 23 \\
\hline 2nd favourite & $3(1.00-3.00)$ & 40 \\
\hline Rating & $4(3.00-4.00)$ & \\
\hline & & \\
\hline
\end{tabular}

